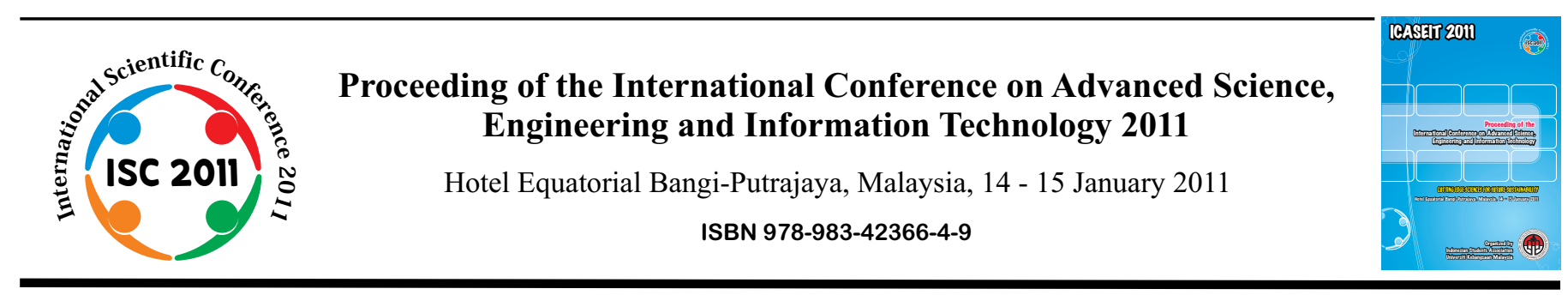

\title{
Direct Fuel Injection of LPG in Small Two-Stroke Engines
}

\author{
Yew Heng Teoh ${ }^{1}$, Horizon Gitano-Briggs ${ }^{2}$ \\ ${ }^{1}$ Faculty of Engineering and Technology, Melaka Campus, Multimedia University \\ Ayer Keroh Lama, Bukit Beruang, 75450, Melaka, Malaysia \\ Tel.:+6012 558-8684, E-mail: henry_teoh3@hotmail.com \\ ${ }^{2}$ School of Mechanical Engineering, Engineering Campus, Universiti Sains Malaysia \\ Seri Ampangan, Nibong Tebal, 14300 Seberang Perai Selatan, Pulau Pinang, Malaysia \\ Tel.:+6016 484-6524,E-mail: horizonUSM@yahoo.com
}

\begin{abstract}
The commonly used carburetted two-stroke engines in developing countries have high exhaust emission and poor fuel efficiency. To meet more rigid emissions requirements, two-stroke vehicles are typically phase out in favour of four-stroke engines. The problems of ubiquitous legacy two-stroke vehicles remain unsolved by these measures and they are likely to be a major source of transport for many years to come. A number of technologies are available for solving the problems associated with two-stroke engines such as catalytic after-treatment and direct fuel injection (DI). However, these solutions are relatively high cost and have shown only slow market acceptance for applications in developing countries. Research in recent years has demonstrated that direct fuel injection is a well developed and readily deployable solution to existing two-stroke engines. Gaseous fuels such as Liquefied Petroleum Gas (LPG) are considered a promising energy source and in many countries provide fuel cost savings. LPG coupled with DI two-stroke technologies, is expected to be clean and cost effective retrofit solution for two-stroke engines. In this research project, direct injection (DI) of Liquefied Petroleum Gas (LPG) is introduced and tested on a typical two-stroke engine. Results of in cylinder combustion pressure translated to fuel mass fraction burned, engine performance and exhaust emissions are taken and compared for various injection timings from premixed (early injection) to fully direct injection mode (late injection). Results show that DI of LPG effectively reduces exhaust hydrocarbon and can substantially improve the fuel economy of two-stroke engines.
\end{abstract}

Keywords - Carburetted, Two-Stroke Engine, Exhaust Emissions, Liquefied Petroleum Gas (LPG), Direct Injection (DI)

\section{INTRODUCTION}

Air quality is deteriorating in many large cities in developing countries at an alarming rate. The rapid growth of the population causes an increasing demand for mobility which has resulted in increased traffic congestion and highly localized air pollution problems in cities. In Asia as a whole it is estimated that there are over 50 million two-stroke cycle engines powering mostly motorcycles/tricycle [1]. The motorcycle/tricycle is one of the most popular modes of transport due to its low purchasing cost, its ease of maneuverable in urban traffic jams and lower operating cost compared to small automobile. These carburetted two-stroke cycle engines are characterized by high levels of carbon monoxide (CO), unburnt hydrocarbon (HC), nitrogen oxides (NOx) and particulate matter (PM), substantially impacting the health of urban residents and deteriorating environmental quality. Various issues related to fuel short-circuiting phenomena, rich tuning, frequent of misfiring and total waste lubrication are the inherent drawbacks of carburetted twostroke engine that cause this type of engines suffers from poor fuel economy and high hydrocarbon emissions.

To address this problem, emissions standards are being adopted for most of the new and in-use vehicle in developing countries. The evolution in emission standards has resulted in shifting in the global motorcycle market towards more fourstroke engines. Four-stroke engines offer better fuel efficiency and lower emissions levels than two-stroke engines as they have no fuel short circuiting. However, four-stroke engines are more complicated than two-stroke engines and have a lower power to weight ratio. To practically offset the problems of two-stroke engines, catalytic converters have been equipped in majority of new two-stroke motorcycle sold in countries such as India, Taiwan and Thailand. In spite of 
that, the issue of the pre-existing or legacy two-stroke cycle vehicles remain unsolved by these measures. These old twostroke tricycles will continue to deteriorate the air quality in urban and rural communities for at least the next eight years [2]. Fig. 1 is a common dirty street scene made up of small two-stroke vehicles. The visible smoke is due to fuel shortcircuiting emitted during scavenging process.

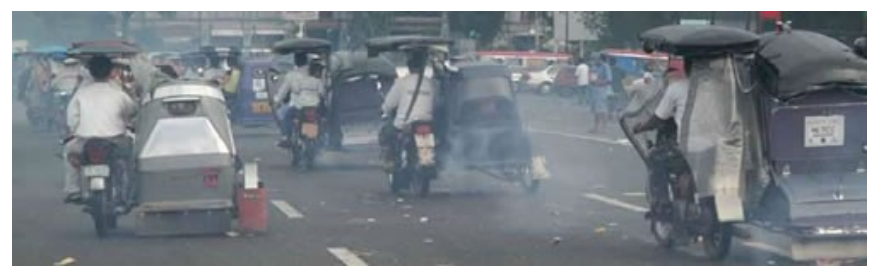

Fig. 1 Air pollution in Manila from small two-stroke powered vehicles [3]

Direct in-cylinder fuel injection (DI) is a fairly mature technology that has shown the ability to greatly reduce emissions from two-stroke engines [4]. Research in recent years has introduced a wide range of Gasoline Direct Injection (GDI) retrofit technologies for small two-stroke engines, including high and low pressure direct injection, air-assisted direct injection and compression pressurized direct injection. Although all the above techniques have been proven to successfully address the high exhaust emission and poor fuel economy issue, market acceptance of commercial available retrofit kits has been slow due to the relatively high price of the conversion kits. One option promising the improvements of GDI as well as lower conversion cost is the gaseous fuel direct injection system. Gaseous fuels such as Liquefied Petroleum Gases (LPG) is held in a pressurized fuel tank (LPG is typically stored at pressures of $400-1500 \mathrm{kPa}$ ). These pressurized fuels can be injected into the cylinder without need for a fuel pump. In addition, air compressor and separate liquid fuel injector can also be eliminated with a gaseous fuel system. Elimination of the major components like air compressor, fuel pump as well as a separate liquid fuel injector will reduce the conversion cost by about $52 \%$ [5].

Retrofitting the gasoline engine to use LPG is an appealing possibility [6]-[8]. Many countries have programs for converting popular two-stroke vehicles to LPG owing to its low fuel price in comparison with gasoline [9]. Typically these conversions consist of simple gaseous carburettors, premixing the fuel with the incoming air [10]. Engines thus converted to premixed LPG are popularly believed to be much cleaner than the original gasoline engine due to a significant reduction in visible smoke produced. They do nothing, however, to address the fuel short-circuiting, and subsequently suffer from both poor fuel efficiency and high hydrocarbon emissions, albeit in the form of a gaseous fuel which is less likely to condense and form visible "smoke". Fig. 2 shows the difference in visible smoke emissions when running on gasoline (top) and LPG premixed (bottom). LPG is a cleaner burning fuel as it generally will reduce the emissions of $\mathrm{CO}$ and many others of the higher molecular weight hazardous air pollutants as LPG is fully vaporized before combustion and consist exclusively of lower molecular weight hydrocarbons.
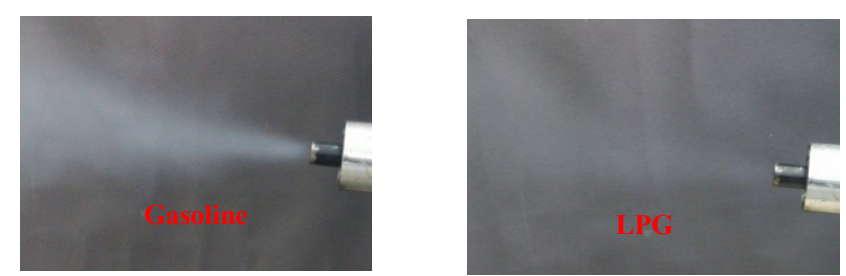

Fig. 2 Exhaust smoke from premixed gasoline (left) and premixed LPG (right). The gasoline powered version has noticeably more exhaust smoke than the LPG fuelled version [11]

Premixed gaseous fuel systems generally have lower power than premixed gasoline systems due to the fuel displacement effect [12]. The research worked by Maxwell et al. measured a total of 10-20\% power loss when injecting a gas into the inlet port [13]. One way to compensate for this phenomenon is to implement direct in-cylinder fuel injection. In addition, LPG fuelled engines generally suffer from slow burning rate as compare to gasoline engines, resulting in an increase in the overall combustion duration, which in turn leads to increased heat transfer losses through cylinder walls and a decrease in the overall thermal efficiency [14]. M.U. Aslam et al. have reported that the maximum brake-torque (MBT) spark timing advance of 2 to $10^{\circ} \mathrm{crank}$ angle is required for gaseous fuelled engine to operate at air-fuel ratios close to stoichiometric [6].

This paper presents the investigation of the direct injection of LPG in terms of lean combustion operation, and focuses on analysis of in cylinder combustion pressure, fuel mass fraction burned, engine performance and exhaust emissions.

\section{Methodology}

\section{ENGINE}

The motorcycle used for these studies is the Modenas Dinamik motorcycle, a carburetted crankcase scavenged twostroke single cylinder with $118 \mathrm{~cm}^{3}$ of displacement. Some of the basic engine parameters are shown in Table 1.

TABLE 1

TECHNICAL SPECIFICATION OF THE MODENAS DINAMIK ENGINE AND YAMAHA RX 100 [15]

\begin{tabular}{|r|l|l|}
\hline Parameter & \multicolumn{1}{|c|}{ Modenas Dinamik } & \multicolumn{1}{|c|}{ Yamaha RX 100 } \\
\hline Engine type & $\begin{array}{l}\text { Single cylinder, } \\
\text { 2 Stroke }\end{array}$ & $\begin{array}{l}\text { Single cylinder, } \\
\text { 2 Stroke }\end{array}$ \\
\hline Engine cooling & Air cooled & Air Cooled \\
\hline Compression ratio & $6.98: 1$ & $6.8: 1$ \\
\hline Bore & $54 \mathrm{~mm}$ & $52.0 \mathrm{~mm}$ \\
\hline Stroke & $51.8 \mathrm{~mm}$ & $45.6 \mathrm{~mm}$ \\
\hline $\begin{array}{r}\text { Displacement } \\
\text { Exhaust port open } \\
\text { (EPO) }\end{array}$ & $118 \mathrm{~cm}^{3}$ & $97 \mathrm{~cm}^{3}$ \\
\hline $\begin{array}{r}\text { Transfer port open } \\
\text { (XPO) }\end{array}$ & $110^{\circ} \mathrm{ATDC}$ & N/A \\
\hline Max. Power & $12.5 \mathrm{~kW} @ 9,000 \mathrm{rpm}$ & $5.3 \mathrm{~kW} @ 6,000 \mathrm{rpm}$ \\
\hline Max. Torque & $14.1 \mathrm{Nm} @ 8,000 \mathrm{rpm}$ & $8.5 \mathrm{Nm}$ @ 5,500rpm \\
\hline
\end{tabular}

For the field run testing of LPG DI system, the Yamaha RX 100 , commonly used tricycle taxis in the Philippines was used. The technical specifications of the vehicle are presented in Table 1. To operate the engine with direct injection (DI), a DI 
head with Synerject Strata 1 air injector was used and mounted on top of the head near the spark plug.

\section{DYNAMOMETER}

A schematic diagram of the engine test cell is shown in Fig. 3. The output sprocket of the engine was coupled to a $20 \mathrm{~kW}$ eddy current type dynamometer to control the engine speed and load.

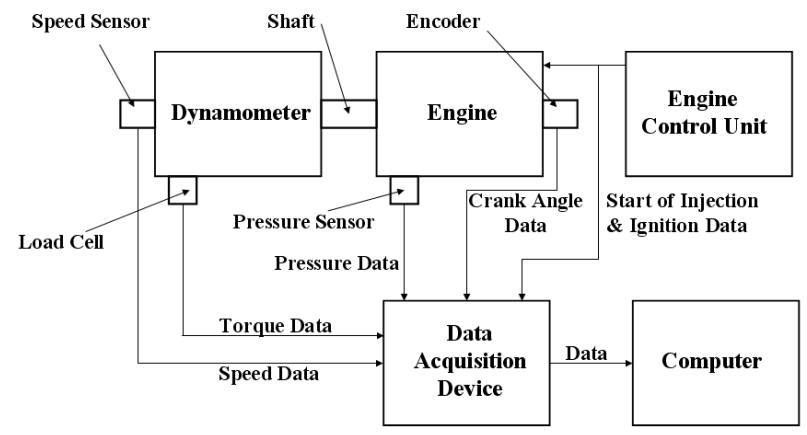

Fig. 3 System overview

\section{IGNITION AND FUEL CONTROL}

The fuel injection controller used for this testing is a custom built dedicated 2-Stroke gaseous fuel Direct Injection ECU by Focus Applied Technologies (FAT). The ECU offer both the option of phasing the end of injection (EOI) timing and ignition timing as a function of engine speed and throttle position. This allows for ignition timing advancement as the system runs on LPG which burns slower than gasoline. The gasoline ignition schedule and the LPG ignition schedule for Modenas Dinamik engine are shown in Fig. 4. Note that the ignition timing has been advanced $5^{\circ}$ from the gasoline schedule for operation with LPG.

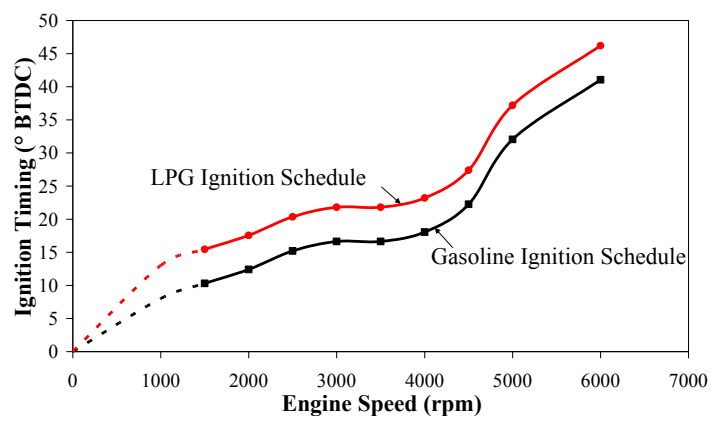

Fig. 4 Ignition timing versus engine speed

Mapping of fuel injection timing is indeed crucial in direct injection system as the degree of air-gaseous fuel mixing is directly related to the engine speed and throttle position. In addition, mixture burning rate is strongly influenced by engine speed, hence mapping of ignition timing as a function of speed is required to attain best engine performance and exhaust emissions [16]. The effect of engine speed on burning rate from a typical spark ignition engine is shown in Fig. 5. The map of end of injection (EOI) timing (a 4 by 8 matrix) and ignition timing ( 1 by 8 matrix) are both presented in Table 2 .

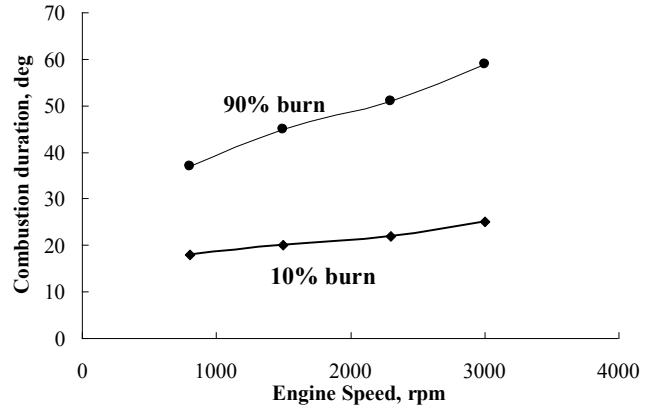

Fig. 5 Effect of engine speed on flame-development angle [16]

TABLE 2

THE MAP OF END OF INJECTION (EOI) TIMING AND IGNITION TIMING

\begin{tabular}{|c|c|c|c|c|c|c|c|c|c|}
\hline $\begin{array}{r}T P S \\
(\%)\end{array}$ & & & & & & & \multicolumn{3}{|c|}{$\begin{array}{l}\text { Ignition timing } \\
\text { map }(1 \times 8)\end{array}$} \\
\hline 100 & 180 & 25 & 14 & 25 & 0 & 0 & $\gamma$ & 0 & \\
\hline 86 & 0 & 184 & 0 & 4 & 2 & 0 & 49 & 53 & \\
\hline 71 & 0 & 0 & 0 & 0 & 0 & 0 & 0 & 0 & \\
\hline 57 & $\lcm{18}$ & 18 & 18 & 17 & 17 & 17 & 17 & 17 & \\
\hline 43 & $220^{-}$ & $2 \pi 0^{-}$ & 200 & $z 0 \sigma$ & $20 \sigma^{-}$ & $20^{\circ}$ & $-195-$ & -195 & \\
\hline 29 & 220 & 210 & 200 & 198 & 197 & 195 & 195 & 195 & \\
\hline 14 & 210 & 210 & 200 & 200 & 207 & 200 & 200 & 200 & \\
\hline 0 & 1200 & 220 & 235 & 230 & 210 & 210 & 160 & 170 I & \\
\hline & $1 \overline{2} 0 \overline{0}$ & $1 \overline{60} 0^{-}$ & 2000 & $\overline{2500}$ & $\overline{3} 0 \overline{00}^{-}$ & $4 \overline{000}$ & $5 \overline{0} 0 \overline{0}$ & $\overline{70} 0 \overline{0}$ & $R P M$ \\
\hline
\end{tabular}

\section{INSTRUMENTATION}

The cylinder pressure was measured using a Kistler $6052 \mathrm{C}$ pressure probe mounted in the combustion chamber. The Data Acquisition Unit (DAQ) is capable of recording up to $500 \mathrm{k}$ samples of data per second. To measure the air mass flow rate to the engine, a Bosch G70 hot wire air flow meter was installed. The LPG used for this study had a tank pressure of $900 \mathrm{kPa}$ with the main constituent being Propane (96\%) and the balanced Butane $(4 \%)$. Fuel pressure was regulated to $650 \mathrm{kPa}$ before injection. Fuel consumption was measured gravimetrically. To accomplish this, the engine is supplied with fuel from a small LPG tank resting on a digital weighing scale. The entire fuel flow monitoring system can be seen in Fig. 6. To analyse the exhaust gasses, a commercial 5-gas analyser was used. Values calculated by the gas analyser do not reflect the trapped air fuel ratio (AFR) due to the fact that the short circuiting of air happens during the scavenging process. The overall AFR of the engine was calculated from the measured air and fuel mass flow rate. Because of shortcircuiting of scavenging air the measured overall AFR is significantly leaner than the trapped AFR in the cylinder.

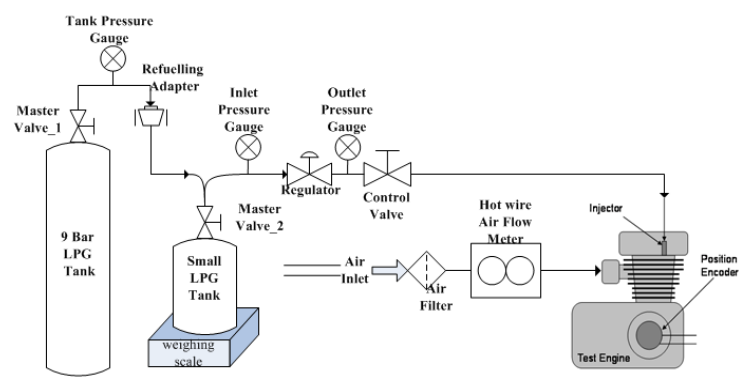

Fig. 6 Schematic overview of the fuel and air supply 


\section{TEST PROCEDURE}

The initial fuel injection timings were developed using Ricardo's WAVE engine modelling software. The model was tuned to give good performance and resulting fuel flow rates were then translated into fuel injection timing maps. Finally the fuel maps were refined based on actual engine performance.

A series of tests were conducted throughout the experiment. In order to run the engine at a slightly lean trapped AFR, the injection duration was held fix at a pulse width (PW) of $1.372 \mathrm{~ms}$ or equivalent to $24.7^{\circ}$ of crank angle at constant engine speed of $3000 \mathrm{rpm}$. Note that the injector PW of $1.372 \mathrm{~ms}$ is denote as medium injection run as it represent slightly lean trapped AFR.

Once the injection duration was held fix, the Start of Injection (SOI) timing was scanned from near BDC (early) to after exhaust port closed at $81^{\circ}$ BTDC (late) as shown in Fig. 7. Throughout the scanning process, exhaust emission, engine torque, air mass flow rate, fuel flow rate and combustion pressure were recorded for further analysis. All measurements were repeated three times at each test setting.

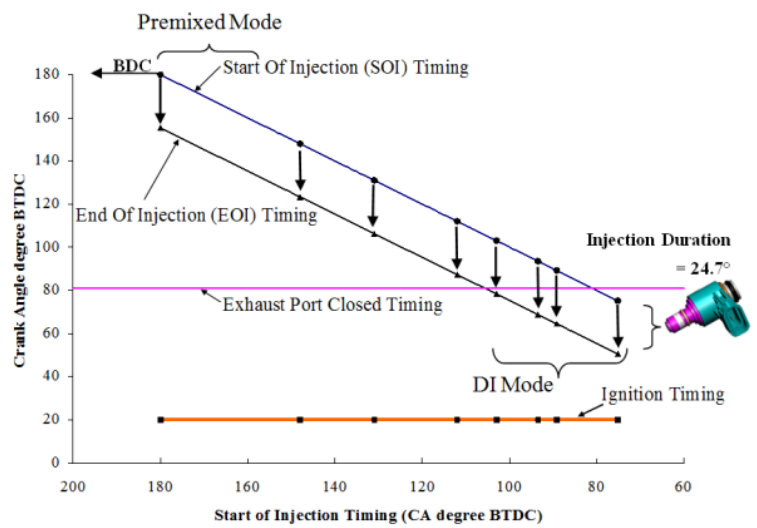

Fig 7 Medium (slightly lean) injection duration under various SOI timing

For leaner of AFR comparison, the injection duration was reduced by $10 \%$ from the medium injection $\mathrm{PW}$ of $1.372 \mathrm{~ms}$, which has results in $1.235 \mathrm{~ms}$ of injector PW or equivalent to $22.2^{\circ}$ of crank angle at constant engine speed of 3000rpm. Note that this leaner injector PW is denote as shorter injection run as it represent leaner trapped AFR. For richer of AFR comparison, the injection duration was increased by $10 \%$ from the medium injection PW of $1.372 \mathrm{~ms}$, which has results in $1.509 \mathrm{~ms}$ of injector PW or equivalent to $27.2^{\circ}$ of crank angle at constant engine speed of $3000 \mathrm{rpm}$. Note that this injector $\mathrm{PW}$ is denote as longer injection run as it represent richer trapped AFR.

\section{RESULTS}

Start of injection (SOI) timing was varied to investigate the capability of LPG as a direct injection fuel in Modenas Dinamik engine. The resulting torque and hydrocarbon (HC) emissions (hexane) are shown in Fig. 8 for the medium injection duration of $1.372 \mathrm{~ms}$, which is equivalent to $24.7^{\circ}$ of crank angle rotation at constant engine speed of 3000rpm.

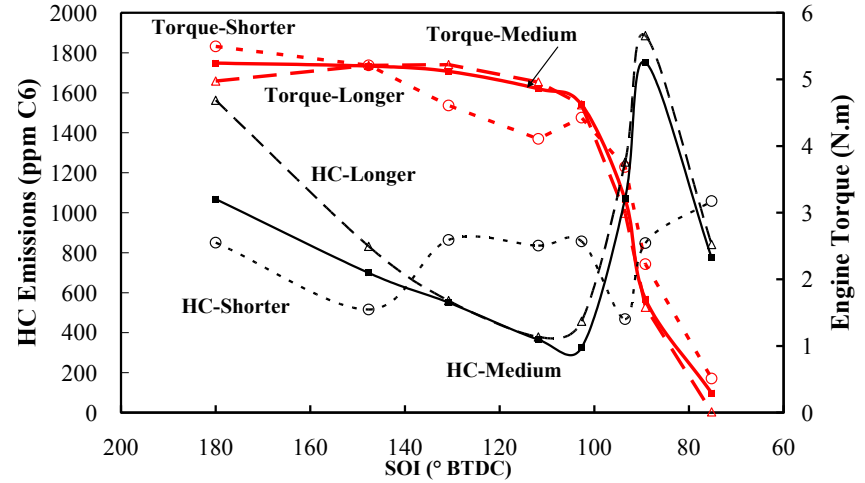

Fig. 8 Torque and HC emissions versus Start of Injection timing for various injection durations

For comparison a $10 \%$ longer duration $\left(27.2^{\circ}\right)$ and $10 \%$ shorter duration $\left(22.2^{\circ}\right)$ were also measured. The overall trend is for torque to drop off sharply with SOI after about $100^{\circ}$ BTDC. HC emissions are minimized at SOI of $100^{\circ}-120^{\circ}$ BTDC, just before the drop in torque. However, there are a lot of subtle details in the data, which will be examined presently. With SOI timing near BDC much of the fuel escapes out at the exhaust port resulting in poor trapping of fuel and high $\mathrm{HC}$ emissions for all runs. For the longer injection durations more fuel will be delivered while the exhaust port and transfer ports are open, displacing greater amounts of air. This fuel displacement effect can be seen in the slight drop in air flow for SOI at $180^{\circ}$ BTDC in Fig. 9. This also accounts for the lower torque for the longer injection durations at SOI of $180^{\circ}$ BTDC as can be seen in Fig. 8 .

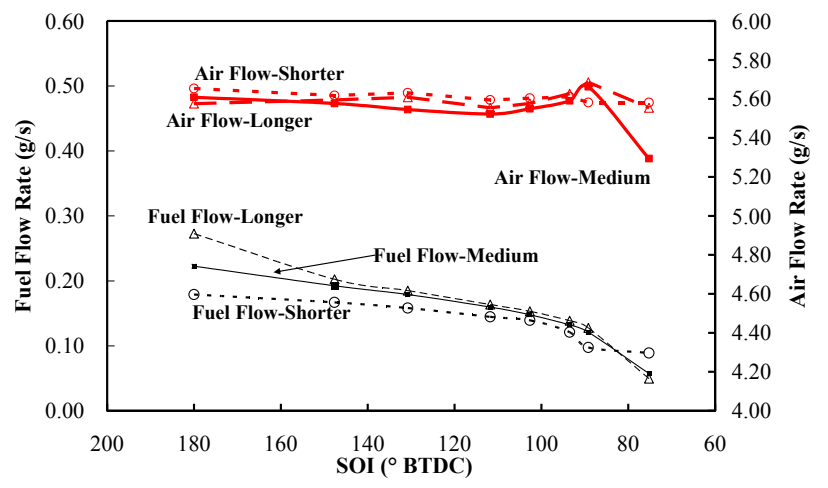

Fig. 9 Fuel and air flow rate versus SOI timing for various injection durations

As $\mathrm{SOI}$ is retarded, $\mathrm{HC}$ emissions drop for all cases as can be seen in Fig. 8. At SOI after $140^{\circ}$ BTDC the short injection duration experiences a large drop in torque and increasing $\mathrm{HC}$ emissions as the e.ngine begins running rough with intermittent misfiring. At this point, the engine has exceeded the lean limit and further enleanment will only result in worse emissions and performance.

With SOI of $130^{\circ}$ BTDC and later the performance of the long and medium injection durations are very similar, with continued decreases in $\mathrm{HC}$ emissions to approximately 325 $\mathrm{ppm}$ at SOI of $100^{\circ}$ to $110^{\circ} \mathrm{BTDC}$. At this point torque has dropped from its maximum value by about $10 \%$. Torque for the longer and medium injection durations begins to decrease sharply after about SOI timing of $100^{\circ}$ BTDC, as HC emissions increase again. The similar levels of $\mathrm{HC}$ emissions for the long and medium injection durations are due to the fact 
that a similar amount of fuel is being delivered, as can be seen in Fig. 9 after SOI timing of $140^{\circ}$ BTDC.

Later SOI gives a sharp decrease in torque and increasing $\mathrm{HC}$ emissions as less mixing time is being provided for the fuel and air to form of combustible mixture. The relative decrease (refer to SOI timing at $180^{\circ} \mathrm{BTDC}$ ) in torque and fuel flow rate with SOI timing for the medium injection duration is shown in Fig. 10. Initially, the torque decreases at a slower rate than the decrease in fuel delivered as SOI timing is retarded. However, torque drops off quickly as SOI timing is shifted from $103^{\circ} \mathrm{BTDC}$ to $93.5^{\circ} \mathrm{BTDC}$ with the decreases of approximately $27 \%$ in torque for a $7 \%$ drop in fuel flow rate. This indicates insufficient time for the fuel and air to mix well as will be further explain in the discussion part.

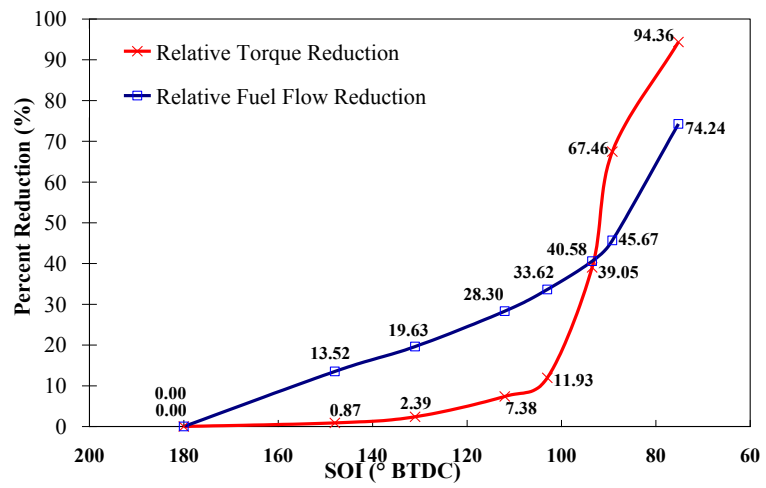

Fig. 10 Percent reduction of torque and fuel flow versus SOI timing for medium injection duration

By referring back to Fig. 8 again, at SOI timings after the exhaust port closed at $81^{\circ}$ BTDC, the torque drops off sharply and the engine begins to misfire aggressively while the fuel delivered into cylinder also decreases, forcing the engine to operate very lean. Eventually $\mathrm{HC}$ emissions drop as fuel delivered decreases further.

A plot of the power and torque produced of the Yamaha RX 100 baseline carburetted gasoline and LPG DI engine are shown in Fig. 11. The peak power is just over $5.3 \mathrm{~kW}$ at 6000 $\mathrm{rpm}$, and the peak torque is approximately $8.5 \mathrm{~N} . \mathrm{m}$ at 5500 $\mathrm{rpm}$ for the carburetted gasoline engine. The results are consistent with the technical specification given in Table 1 . Besides, the LPG DI produced a peak power of $5.2 \mathrm{~kW}$ at $6000 \mathrm{rpm}$, and a peak torque of $8.3 \mathrm{~N} . \mathrm{m}$ at $6000 \mathrm{rpm}$. Note that LPG DI produced about $100 \mathrm{~W}$ lower power than the carburetted gasoline engine at $6000 \mathrm{rpm}$. The LPG DI system gave a flatter torque curve in the range of 3000 to $4000 \mathrm{rpm}$ than the carburetted gasoline engine. This higher torque at the low end gives more low-end acceleration improving drivability.

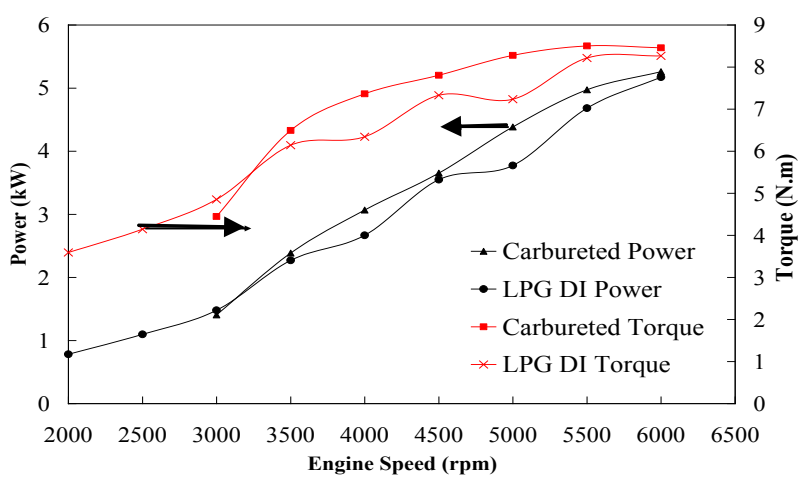

Fig. 11 Carburetted gasoline and LPG DI engine power and torque as a function of engine speed, wide open throttle (WOT)

To quantify the improvements in emissions the LPG DI was tested for emissions and compared to the baseline carburetted gasoline engine. Fig. 12 shows the emissions of the two systems at various engine speeds at WOT. Obviously the carburetted system has high HC emissions (Fig. 12a) across the board as it suffers from fuel short-circuiting. The LPG DI's hydrocarbon emissions are about half of the carburetted system at engine speeds of $4500 \mathrm{rpm}$ and above, but is comparable at lower engine speed. This is due to the fuel short-circuiting at lower engine speed as there is sufficient time for the fuel to travel across the cylinder and escape via the exhaust port. Also notice that at engine speed of 3500 to $4000 \mathrm{rpm}$, while both of the systems have the same exhaust air to fuel ratio (AFR) (Fig. 12d), the LPG DI gives lower $\mathrm{HC}$ emissions than the carburetted gasoline. This again shows improved trapping of fuel in LPG DI system.
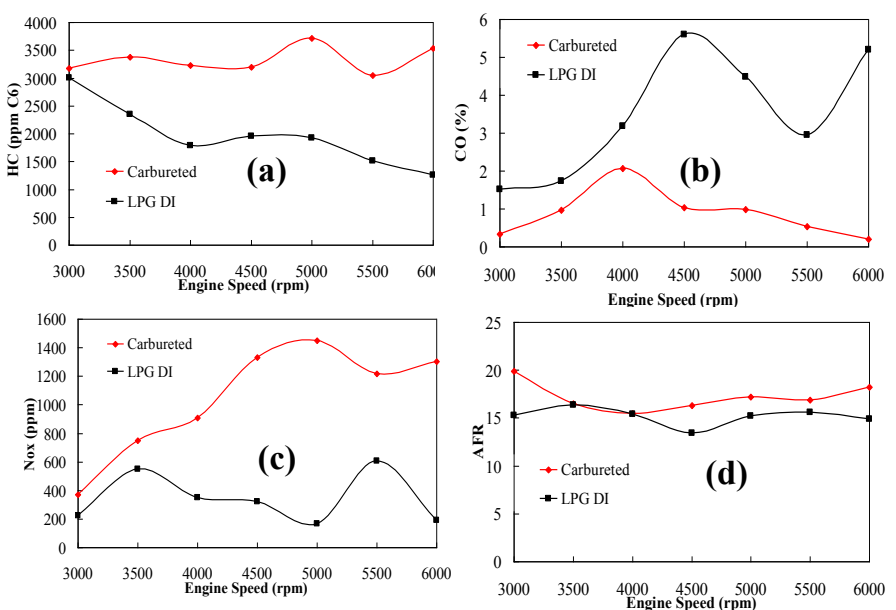

Fig. 12 Emissions of the carburetted and LPG DI systems at various engine speeds, WOT: (a) HC; (b) CO; (c) NOx \& (d) AFR

Carbon Monoxide (CO) emissions (Fig. 12b) were high for the LPG DI techniques as it is run slightly rich to protect the engine from damage. This can be seen from the listed AFR data (Fig. 12d). The engine will suffer from heavy knocking (pre-ignition) if it is operated in lean mode at high loads. Besides, at engine speeds of 3500 to $4000 \mathrm{rpm}$, while both of the systems have the same exhaust AFR, the LPG DI has higher $\mathrm{CO}$ emissions than the carburetted gasoline. This is due to poor mixing between fuel and air in LPG DI system, hence caused incomplete combustion as a result of higher degree of stratification. Finally the LPG DI techniques had lower Nitrogen Oxides (NOx) emissions (Fig. 12c) compare to the 
carburetted engine. This again is associated with the relatively rich tuning of the LPG DI engine.

\section{DISCUSSIONS}

As mentioned previously, the $\mathrm{HC}$ emissions are minimized with SOI timings significantly earlier than exhaust port close timing at $81^{\circ}$ BTDC. Several factors affect this. For one the injector has a latency (delay between the electrical injection signal and the actual fuel flow) of approximately $0.6 \mathrm{~ms}$ or about $10^{\circ}$ of crank angle at 3000rpm [17]-[18]. Additionally there is a propagation delay before the injected gas can reach the exhaust port. Given the $10^{\circ}$ of latency in the injector and another $10^{\circ}$ of gas transport delay, this will result in total of $20^{\circ}$ shifting in injection timing before short circuiting can occur [19]. To achieve maximum fuel trapping, SOI should thus be set to $81^{\circ}+20^{\circ}$ or about $101^{\circ}$ BTDC. This is consistent with our observation of minimum $\mathrm{HC}$ emissions occurring significantly before EPC.

From the data acquired, the $\mathrm{HC}$ and $\mathrm{CO}$ emissions vary as SOI timing is retarded. Throughout the scan of SOI timing from very early near BDC to after EPC, the trapped air to fuel ratio varies significantly. Numerous factors affect the trapped AFR, torque and emissions namely fuel short-circuiting enleanment, compression pressure enleanment and late mixing. Fig. 13 shows a graphical description of short-circuiting enleanment as a function of SOI timing and injection duration. The curve indicates the combustion chamber pressure which increases with compression after EPC. EPC is at $81^{\circ} \mathrm{BTDC}$, but due to injector latency and propagation delay from the injector to the exhaust port, the effective exhaust port close timing (EEPC) is moved to $101^{\circ}$ BTDC. Fuel injected prior to this is subject to short circuiting while after EEPC fuel is effectively trapped in the combustion chamber. At the early injection timing of $\mathrm{SOI}=112^{\circ} \mathrm{BTDC}$, the amount of trapped fuel after $101^{\circ} \mathrm{BTDC}$ is much less than in later injection timing of $\mathrm{SOI}=103^{\circ} \mathrm{BTDC}$. Unburned $\mathrm{HC}$ emissions levels are expected to be much worse for the early injection compared to later injection cases. This phenomenon is consistent with our observation of $\mathrm{HC}$ emissions decrease as SOI is retarded.

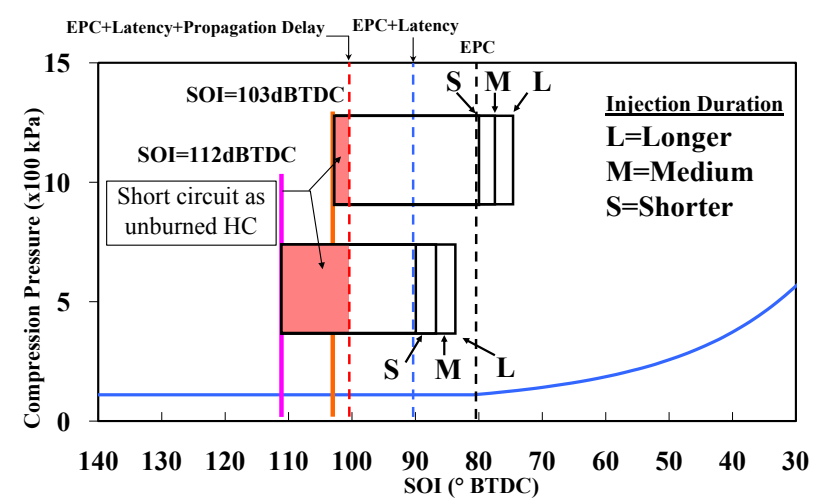

Fig. 13 Illustration of fuel short circuiting enleanment at two SOI timings

Another significant effect occurring when SOI timing is moved very late is the enleanment cause by compression pressure. The amount of fuel deliver into the combustion chamber is proportional to the difference in pressure between the injection pressure $(650 \mathrm{kPa})$ and the combustion chamber pressure. Combustion chamber pressure increases after EPC due to compression of the gases trapped in the combustion chamber. This will reduce the pressure different across the injector and subsequently reduce the fuel flow rate. Fig. 14 shows various duration injection events for late SOI timing of 93.5 $5^{\circ}$ BTDC. The bold curve represents the normal combustion chamber pressure. The finer curve is the combustion chamber pressure shifted $10^{\circ}$ to reflect the injector latency. Three different injections durations are illustrated at the same SOI timing of $93.5^{\circ}$ BTDC. In each case, the fuel flow is reduced as combustion chamber pressure builds. The shaded area indicates fuel delivery while the lighter portion of the fuel injection envelope represents enleanment due to compression encroachment. In the case shown both the medium (M) injection and the long injection duration (L) will have similar actual fuel delivery quantities. Fuel from the additional injector duration of the long injection is obviated by the increased compression pressure. This should lead to a reduction of fuel flow as SOI is retarded. As fuel delivery is reduced a drop in torque will be expected as well. The rapid drop in fuel flow of Fig. 9 after SOI of about $90^{\circ}$ BTDC is only partially responsible for the sharp drop in torque of Fig. 8. It can be seen that torque begins dropping at around $100^{\circ} \mathrm{BTDC}$, i.e. before the major reduction of fuel flow.

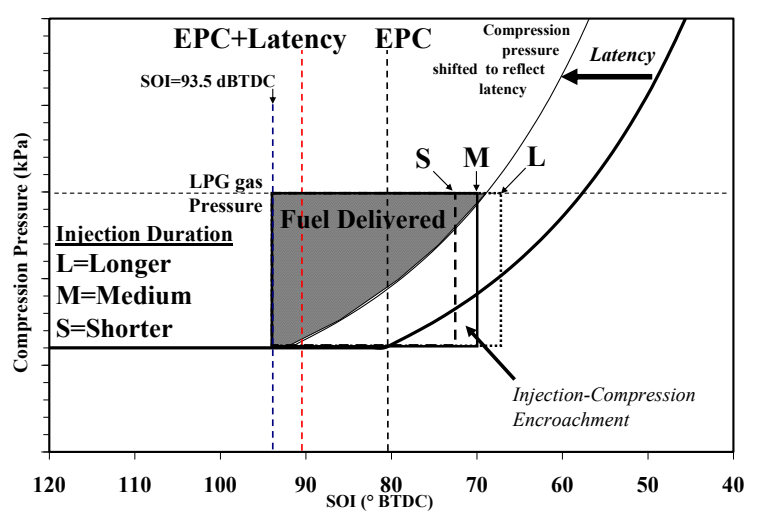

Fig. 14 Graphical explanation of the effect of compression pressure enleanment for various injection durations

The air/fuel mixing effect only begins to reveal it's self at late SOI timings. Fuel injected early will have enough time to mix and distribute itself about the combustion chamber more or less homogenously. As injection timing is retarded, less time is available for mixing, resulting in a higher degree of stratification with more incombustible lean and rich pockets. This non-homogenous mixture will have a hard time igniting, exhibit lower flame speeds and the torque, and higher $\mathrm{HC}$ emissions as fuel rich pockets are left partially unburned. Although it will have a gradual onset in practice, we can envision this effect as a timing limit before which the air/fuel mixture is primarily homogenous, and after which it is more stratified. For fuel delivered before it mixing limit, we would expect good mixing, and thus reasonably good torque and low emissions. This situation is illustrated in Fig. 15. 


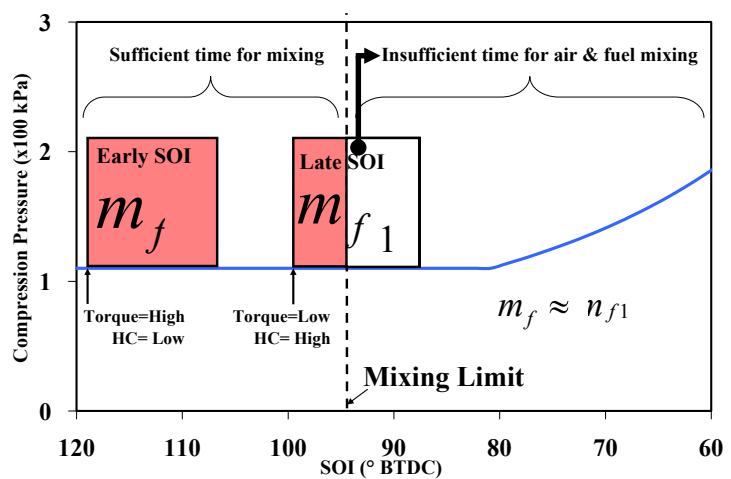

Fig. 15 Illustration of mixing limit on charge homogeneity

The early injection is well mixed but the later injection, though it delivers a similar amount of fuel, will be at least partially poorly mixed and thus have a slower flame speed, lower torque and higher emissions. For very late injections this may also result in misfiring as well.

Mass Fraction Burned (MBF) curves, Fig. 16, were calculated from the combustion pressure data. The slope of the curve is directly related with the flame speed. The more homogenous (early) mixture burns more rapidly resulting in a higher peak pressure occurring earlier. And onset of the rapid burn section is delayed as well. The later injection has a much slower flame speed, indicating poorer mixing. This indicates that for the operational point investigated, the mixing limit lies in the area of $100^{\circ}$ BTDC. This is the major reason for the drop of torque in Fig. 8 around SOI of $100^{\circ}$ BTDC.

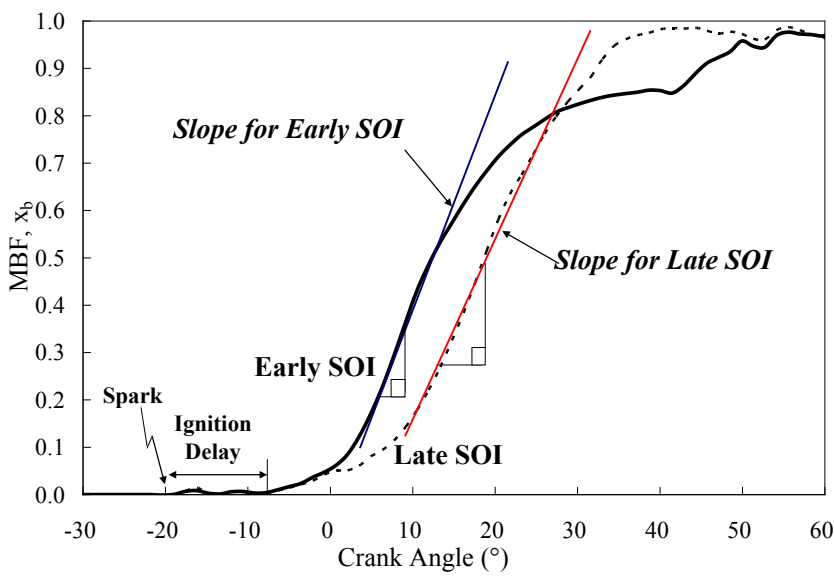

Fig. 16 Mass fraction burned $\left(\mathrm{x}_{\mathrm{b}}\right)$ as a function of crank angle for early and late SOI timing. Ignition timing is $20^{\circ} \mathrm{BTDC}, 30 \%$ throttle, $3000 \mathrm{rpm}$

\section{CONCLUSIONS}

The carburetted, crankcase scavenged two-stroke engine has been successfully converted to LPG direct fuel injection. The lean operation via fully stratified combustion was not achieved due to misfiring and poor mixing of air and fuel with late injection timing. Subsequently, the overall best SOI timing for optimum fuel consumption and exhaust emission is approximately $103^{\circ} \mathrm{BTDC}$ for operational at 3000rpm and $1.5 \mathrm{~kW}$. Finally, Direct Injection of propane can reduce HC emissions to approximately $325 \mathrm{ppm}$

\section{REFERENCES}

[1] N. Lorenz, T. Bauer, and B. Willson, Design of a Direct Injection Retrofit Kit for Small Two-Stroke Engines. In: Small Engine Technology Conference \& Exposition, October 2005, Bangkok THAILAND, Warrendale, PA, Society of Automotive Engineers. SAE 2005-32-0095, 2005.

[2] J.B.M. Biona, A.B. Culaba, R.R. Tan and M.R.I. Purvis, Possibilistic fuel cycle assessment of retrofit technologies for two stroke powered tricycles, Transportation Research Part D, vol. 13, pp.306-314, 2008.

[3] (2010) Envirofit Technology- 2-Stroke Retrofit website. [Online] Available:http://www.envirofit.org/?q=our-products/2-strokeretrofit/technology

[4] G.P Blair, Design and Simulation of Two-Stroke Engines. Warrendale, PA: Society of Automotive Engineers (SAE), 1996.

[5] Y.H. Teoh, H.W. Gitano, and K.F. Mustafa, Performance Characterization of a Direct Injection LPG Fuelled Two-Stroke Motorcycle Engine. In: Small Engine Technology Conference and Exhibition, September 2008, Milwaukee, WI, USA. Warrendale, PA, Society of Automotive Engineers. SAE 2008-32-0045, 2008.

[6] M.U. Aslam, H.H. Masjuki, M.A. Kalam, H. Abdesselam, T.M.I. Mahlia and M.A. Amalina, An experimental investigation of $C N G$ as an alternative fuel for a retrofitted gasoline vehicle. FUEL. Volume (85), Issues 5-6, p.717-724, 2006.

[7] H. Bayraktar, and O. Durgan, Investigating the effects of LPG on spark ignition engine combustion and performance. Energy Conversion \& Management. vol. 46, Issues 13-14, p.2317-2333, 2005.

[8] V.G. Bui, V.N. Tran, T.Q. Ho and T.D.P. Pham, APPLICATION OF LPG ON MOTORCYCLE AND SMALL SIZED BUS. In: Conference of Clean Fuels and Vehicle in Vietnam, Hanoi, Vietnam, 13-14 May 2004.

[9] The World Bank, Improving Urban Air Quality in South Asia by Reducing Emissions from Two-Stroke Engine Vehicles (2000) [Online], [Accessed 22nd March 2010]. Available from World Wide Web:http://siteresources.worldbank.org/INTURBANTRANSPORT/Re sources/2str1201improving.pdf.

[10] (2010) Klockner LPG Gas Converter, Project Report on Manufacturing Unit of Klockner LPG Gas Converter Kit for Outboard Engines, Speed Boats, Fishing Boats \& Adventure Sports Craft [Online]. Available: http://www.gastechproducts.com/outboat.html

[11] H.W. Gitano, Y.H. Teoh, K.F. Mustafa, C.Y. Sew, LPG Direct Injection: An Alternative Fuel Solution to the Two-Stroke Emissions Problem. In: Small Engine Technology Conference and Exhibition, October 2007, Niigata, Japan. Warrendale, PA, Society of Automotive Engineers. SAE 2007-32-0024, 2007.

[12] M.A. Ceviz and F. Yüksel, Cyclic variations on LPG and gasolinefuelled lean burn SI engine. Renewable Energy. vol. 31, p.1950-1960, 2006.

[13] T.T. Maxwell and J.C. Jones, Alternative fuels: Emissions, Economic and Performance. Warrendale, PA, Society of Automotive Engineers SAE Inc., 1995

[14] D. Lee, J. Shaka, S. Goto, H. Ishikawa, H. Ueno and N. Harayama, Observation of Flame Propagation in an LPG Lean Burn SI Engine. In: International Congress \& Exposition, March 1999, Detroit, MI, USA, Warrendale, PA, Society of Automotive Engineers. SAE 1999-01-0570, 1999.

[15] (2008) Modenas [Online], Available: http://www.modenas.com.my/v2motorcycle.asp?id=46

[16] J.B. Heywood, Internal Combustion Engine Fundamentals. Singapore: McGraw-Hill, 1988

[17] R. Shiina, H. Suzuki, M. Araki, H. Nakamura, S. Shiga and H. Kishimoto, Application of Scavenging-Port Injection of CNG to a Boat Engine at Running Conditions. In: Small Engine Technology Conference and Exhibition, November 2009, Penang, Malaysia. Warrendale, PA, Society of Automotive Engineers. SAE 2009-32-0077, 2009

[18] F. Zhao, D.L. Harrington and M.C. Lai, Automotive Gasoline DirectInjection Engines. Warrendale, PA: Society of Automotive Engineers (SAE), 2002.

[19] Y.H. Teoh, H.W. Gitano and Y.H. Tan, Development of the Gaseous Fuel Direct Injection System for Small Two-Stroke Transports. In: Small Engine Technology Conference and Exhibition, November 2009 Penang, Malaysia. Warrendale, PA, Society of Automotive Engineers. SAE 2009-32-0032, 2009 